\title{
Paying before or paying after? Timing and uncertainty in pay-what-you- want pricing
}

Viglia Giampaolo ${ }^{\mathrm{a}, 1}$, Maras Marta ${ }^{\mathrm{b}}$, Schumann Jan $^{\mathrm{c}}$, Navarro-Martinez Daniel $^{\mathrm{d}}$

Keywords: PWYW; time of payment; uncertainty; profitability; services

\footnotetext{
${ }^{a}$ University of Portsmouth, Department of Marketing and Sales, Richmond Building Portland Street, PO13DE Portsmouth, United Kingdom

${ }^{\mathrm{b}}$ Gettysburg College, Department of Management, 300 North Washington Street, 17325

Gettysburg, Pennsylvania

${ }^{\mathrm{c}}$ University of Passau, Department of Marketing and Innovation, Innstraße 27, 94032 Passau, Germany

${ }^{\mathrm{d}}$ Pompeu Fabra University, Department of Economics and Business, Ramon Trias Fargas 25-27, 08005 Barcelona, Spain
}

\footnotetext{
${ }^{1}$ giampaolo.viglia@port.ac.uk corresponding author.
} 


\title{
Paying before or paying after? Timing and uncertainty in pay-what-you-want pricing
}

\begin{abstract}
Pay what you want (PWYW) is a relatively new and promising pricing mechanism, where consumers have full control over the price they pay. It can potentially increase profits, but its practical applications have produced mixed results. The time of payment, and its implications for consumer uncertainty, might constitute an important determinant of the profitability of such pricing schemes for service providers. A large field experiment conducted in conventional and fast-food restaurants provides initial support that paying after consumption increases PWYW amounts. A laboratory study then details the underlying psychological process; payments after consumption help resolve uncertainty about the service process and service outcome. Another field experiment affirms these insights and further shows that PWYW after consumption, compared with fixed pricing, can increase profitability due to enhanced service capacity utilization. By detailing how timing and uncertainty reduction affect consumers' chosen payments, this article contributes to PWYW research in particular, as well as more general literature pertaining to the dynamics that affect consumers' service experiences and service pricing studies.
\end{abstract}

KEYWORDS: PWYW; time of payment; uncertainty; profitability; services 
Pay-what-you-want (PWYW) pricing mechanisms offer a new way for sellers to leverage price discrimination tactics and penetrate markets. The mechanism delegates the pricing decision to consumers, who may pay any price they choose, including nothing (Kim, Natter, and Spann 2009). In service settings, PWYW is becoming particularly popular, appearing in diverse contexts such as restaurants (Kim, Natter, and Spann 2010), hotels (Léon, Noguera, and Tena-Sanchez 2012), music (Johnson and Cui 2013; Regner and Barria 2009), tourism packages (Stangl and Prayag 2018), and amusement parks (Gneezy et al. 2010). Many companies have embraced PWYW as a means to promote their new presence in the market, signal their social responsibility, manage their capacity utilization, and increase their profitability.

Yet for service providers the PWYW mechanism also involves an inherent risk, in that consumers could pay (on average) much less for the services than they would with a conventional pricing approach (e.g., Kim, Natter, and Spann 2009; Kim, Kaufmann, and Stegemann 2014). This risk might be worth it if the appeal of PWYW increases the number of customers (Riener and Traxler, 2012), leading to a net positive effect on profitability. Still, the successful implementation of PWYW pricing is challenging, as the notably unsuccessful cases of Panera Bread and Lyft's ride-sharing service show (De Pillis 2017). In these cases, PWYW actually resulted in substantial losses, such that the companies ultimately ended their experiments with the pricing mechanism. Service managers need a better understanding of the factors that determine PWYW profitability.

Some evidence offers insights into various contingency factors (Gneezy et al. 2010; Johnson and Cui 2013; Kim, Natter, and Spann 2009; Schmidt, Spann, and Zeithammer 2015), such as the value of the service offering (Kim, Kaufmann, and Stegemann 2014), exposure to external reference prices (Johnson and Cui 2013), feelings of guilt (Kunter 2015), whether the offering includes a pro-social dimension (Gneezy et al. 2010), and 
information about sellers' costs and payments made by others (Jang and Chu 2012; Riener and Traxler 2012). We seek to extend these insights by proposing a novel contingency factor, namely, the payment timing and its impact on consumer uncertainty. We define payment timing according to whether the payment takes place before or after consumption; Panera Bread requested that diners pay what they wanted before consuming their meals; AccorHotels instead asked guests to pay after staying in its hotels in Paris and Delhi (Pay What You Want Ibis 2015). We know of no research that investigates payment timing in PWYW contexts, yet the real-world evidence we summarize in Table 1 suggests that in many prominent PWYW industry applications, timing the PWYW before or after consumption affects its profitability.

\section{[INSERT TABLE 1 HERE]}

When businesses have implemented PWYW before consumption, it has been profitable in settings that involve charitable giving. However, these results are not found in for-profit business settings. Panera Bread (DePillis 2017), cinemas (Kim, Natter, and Spann 2009), and cafeterias (Kim, Kaufmann, and Stegemann 2014) found that PWYW prices paid before consumption were significantly lower than regular prices paid - and these businesses discontinued use of PWYW. In contrast, most businesses that implemented PWYW after consumption continue to use PWYW and have earned increased returns from it.

This anecdotal evidence of the benefits of post-consumption PWYW timing resonates with dynamic models of service usage (Bolton and Lemon 1999; Bolton, Lemon, and Bramlett 2006; Iyengar, Ansari, and Gupta 2007; Rust et al. 1999), as well as conceptual and cognitive models of service marketing (Oliver 1980; Parasuraman, Zeithaml, and Berry 1985). Higher PWYW payments after a service experience might emerge because this timing scenario reduces consumers' uncertainty about both the service process and the 
service outcome. Across three studies, we confirm that PWYW payments are higher when they take place after the service experience. This effect is moderated by the uncertainty associated with the service, such that differences in PWYW payments due to timing are greater in service settings marked by high customer uncertainty (conventional restaurant) than in those that induce relatively lower customer uncertainty (fast-food restaurant).

In Study 1, we tested our hypotheses in a large field experiment conducted over a twoweek period, during which we implemented PWYW payments before and after consumption. We compared two contexts - a conventional and a fast-food restaurant that have high and low levels of uncertainty respectively- and find that the magnitude of the effect of payment timing depends on the amount of uncertainty inherent in the service context. In Study 2, we distinguished between two kinds of uncertainty: process versus outcome uncertainty. In that experimental study, we presented participants with hypothetical scenarios that manipulated the uncertainty of the service process and uncertainty of the outcome (i.e., food quality). In Study 3, we conducted a field experiment that extended our research to a different industry setting: a photo service on a cruise ship.

This article shows that PWYW can increase profitability relative to fixed pricing when payments are made after consumption, with greater effects in high uncertainty contexts. Moreover, it is effective when there is uncertainty with respect to the process or the outcome or both. We also show that PWYW provides an opportunity to increase service capacity utilization and thereby increase profitability. By using multiple methods, we enhance both the convergent validity and the external validity of our findings - and we are able to offer guidelines for managers on how to implement PWYW pricing.

This study makes four contributions to service research and pricing practice. First, we introduce payment timing as an important element of PWYW pricing mechanism, thereby extending research on this topic (Kim, Natter, and Spann 2009, Gneezy et al. 2010; Stangl 
and Prayag 2018). Across three studies, we confirm that paying after consumption increases average consumers' PWYW payments compared with paying before consumption. Second, we advance knowledge about PWYW profitability. Prior studies offer some contrasting findings (Chao, Fernandez, and Nahata 2015; Gneezy et al. 2012); we establish meaningful boundary conditions based on timing and uncertainty reduction. Third, in relation to the general service literature, we explicate novel dynamics in consumers' service experiences and perceptions (Bolton and Lemon 1999; Bolton, Lemon, and Bramlett 2006; Iyengar, Ansari, and Gupta 2007; Rust et al. 1999) by showing how the amount paid can increase after a usage experience. Fourth, we contribute to service pricing research by providing further evidence for the need to reduce consumer uncertainty. In this effort, we offer a price tag for uncertainty reduction (Hogreve and Gremler 2009) and relate our findings to some previously identified consumer pricing anomalies, such as the flat-rate bias (Lambrecht and Skiera 2006).

\section{THEORETICAL BACKGROUND}

Compared with goods, services evoke strong information asymmetries, because consumers can assess the quality of a service only after its consumption (Murray 1991; Papakonstantinou and Bogetoft 2017; Parasuraman, Zeithaml, and Berry 1985). Dynamic models of service usage show that, to make informed decisions, service customers update their service-related beliefs, using timing and uncertainty as input factors (Bolton and Lemon 1999; Bolton, Lemon, and Bramlett 2006; Iyengar, Ansari, and Gupta 2007; Rust et al. 1999). Bolton and Lemon (1999) establish that consumers constantly monitor their service usage, evaluating the "get" component of the exchange relative to the "give" component. As a result, they develop fairness perceptions that affect their future usage behavior. Bolton, Lemon, and Bramlett (2006) also demonstrate the influence of timing: More recent experiences weigh more heavily than earlier ones. In addition, Rust et al. 
(1999) recognize that consumers evaluate service experience not in absolute terms but rather by considering the variance and uncertainty of the experience, such that they reward lower levels of uncertainty (i.e., lower variance of the expectations distribution). By calculating an uncertainty reduction premium, Iyengar et al. (2007) specify how uncertainty reduction can increase consumers' lifetime value.

Uncertainty reduction also is central to the so-called flat-rate bias, an anomaly by which consumers are willing to pay a higher fixed amount upfront rather than agree to a more uncertain, pay per unit rate, even if the latter is more economical (Lambrecht and Skiera 2006). Recent studies also confirm that consumers will pay a premium price for the same service if the service provider can reduce their uncertainty (Liu et al. 2015). This effect likely explains the longstanding success of service guarantees, which provide competitive advantages to firms that use them to reduce consumer uncertainty (Hogreve and Gremler 2009). Because uncertainty resolution is such a key driver of the service experience, we anticipate that it affects service consumers' willingness to pay in PWYW settings as well. Although some prior research identifies uncertainty as a potentially important variable for the PWYW domain (Spann et al. 2018; Weisstein, Kukar-Kinney, and Monroe 2016), its effect has not been investigated systematically.

Even if customers have some information about the service (e.g., from reading restaurant reviews), they cannot predict the precise quality level of any specific service process and service outcome due to the inherent heterogeneity of services (Parasuraman, Zeithaml, and Berry 1985). Therefore, service providers rely on different signals, including price, advertising, brand names, warranties, or corporate social responsibility, to convey information about service quality and reduce uncertainty (Akdeniz, Calantone, and Voorhies 2014). In traditional pricing settings, the price set by the seller can serve as a signal of service quality; in PWYW contexts, by definition, the price cannot serve this 
function. Thus consumers might experience greater uncertainty about service quality, leading them to prefer to pay, on average, lower amounts before their consumption. However, if the seller uses a PWYW pricing mechanism post-consumption, most of this uncertainty will have been resolved. Therefore, we predict:

H1: There is a positive effect of payment timing on PWYW payments in services such that average PWYW payments after service consumption are higher than average PWYW payments before service consumption.

The separation between purchase and consumption creates uncertainty about the utility of the consumption (Shugan and Xie 2000). Rust et al. (1999) show that it is not necessary to exceed customer expectations to increase preference, in that customers are willing to trade off some quality providing the service is more certain. Therefore, in a PWYW context, finding tactical ways to reduce customers' uncertainty is particularly important. We consider two main categories of uncertainty: about the service process and about the service outcome, such as the quality of the food in restaurant service settings. Both sources of uncertainty could qualify the effects of payment timing on PWYW payments such that in high-uncertainty contexts, consumers may be even more likely to seek to reduce their before-consumption payments, relative to their after-consumption payments. That is, the difference in chosen payments when consumers engage in PWYW before versus paying after consumption should be greater in high- than in low-uncertainty contexts. Formally,

H2: The effect of payment timing on PWYW payments is contingent on the level of uncertainty associated with the service such that there is a stronger payment timing effect in high-uncertainty contexts than in low-uncertainty contexts.

Figure 1 presents the conceptual framework and its application across the three studies we report in this article. In field Study 1, we test our core prediction that customers tend to 
pay more after consumption than before consumption, as well as the moderating role of uncertainty on this effect. With Study 2, we keep the timing fixed but explore the role of uncertainty in more detail, looking at two separate uncertainty components, namely, uncertainty toward the service outcome and uncertainty toward the service process. Finally, with Study 3 we extend the service setting to help generalize our findings that the profitability of PWYW, as compared with a fixed pricing mechanism, depends on payment timing. This final study also highlights implications of our work for capacity management (Ng, Wirtz, and Lee 1999; Wirtz and Zeithaml 2018), especially for service firms that often struggle with unused service capacity and variable demand (Moeller 2010; Thompson 2015).

[INSERT FIGURE 1 HERE]

\section{STUDY 1: RESTAURANT FIELD STUDY TESTING H1 and H2}

\section{Data Collection and Sample}

We conducted Study 1 in two restaurants run by the same owner: a conventional, average quality, sit-down, family-owned Italian restaurant and a fast-food restaurant, both located in Piedmont, Italy. During May and June 2014, for a period of two weeks, the owner offered meals under PWYW conditions for both lunch and dinner in the conventional restaurant and for the entire day in the fast-food restaurant. Consumers could pay any amount they wanted for their meals. They paid separately for the beverages, according to a standard fixed pricing system. To avoid effects of consumers' self-selection, the PWYW pricing mechanism was not advertised. A total of 296 customers consumed a meal at the conventional restaurant and 301 customers ate at the fast-food restaurant during the two weeks of the experiment.

Design and Procedures 
We implemented two PWYW conditions, one in which customers paid before consumption (before condition) and another in which they paid after (after condition). In both conditions, customers learned of the PWYW mechanism when they arrived at the restaurants or received the menus. Waiters received consistent instructions about how to explain the PWYW mechanism to customers. The menus had no prices listed or recommended. Customers ordered their meals by marking their choices (individually) on carbon paper menus, so a copy of their choices was generated automatically. The customers in the fast-food restaurant could see the dishes available in a counter display, but the customers of the conventional restaurant could not.

In the before condition, when customers finished ordering, waiters asked them to write down the total price they wanted to pay for the meal in a space at the bottom of the paper menu. The waiters stepped away, so that the consumers did not have to write down the PWYW amounts in the presence of the waiters, then returned and took the carbon copy to the kitchen (conventional restaurant) or back to the counter (fast-food restaurant), while customers kept a paper copy. In the after condition, customers ordered and handed both copies to the waiters. After they had finished their meal and asked for the check, waiters returned the paper copy of the menu and retained the carbon copy, then asked the consumers to write down the price they wanted to pay for the meal.

In both conditions, to guarantee anonymity and avoid fears of retaliation, as soon as consumers wrote down their PWYW amount, they were instructed to place it in a cardboard box located on their table. The box had a small slot on the top, so consumers could not retrieve the menus, and the PWYW amounts were private and binding. Next, they received a short, individual survey to complete, either when they finished their meal (before condition) or after they chose their PWYW amount (after condition). When they were ready to pay, they took both the box and the survey to the cashier, who linked the 
survey responses to the paper menus in the box, using a unique identifier for each customer.

To avoid systematic time effects in the conventional restaurant, the before and after conditions alternated across lunch and dinner on the experimental days; on a day with the PWYW before condition at lunch, the dinner service featured the PWYW after condition, and vice versa. In the fast-food restaurant, no break occurred between lunch and dinner service, so the before and after conditions were randomized across days. The fast-food restaurant also had some distinctive features that we took into consideration in designing the experiment. First, it provides takeout services, and these consumers by definition enter the before condition; they must pay before they leave with their food to consume it. To avoid selection issues and for the sake of comparability, we therefore excluded takeout customers and performed our analysis solely with 145 sit-down customers. Second, unlike the conventional restaurant, the transactions in fast-food restaurants are brief (Jerger and Wirtz 2017; Mattila and Enz 2002), and they entail considerably less uncertainty about the service outcome (food) and service process. Specifically, the restaurant in this study offers standardized, precooked food that is visible before consumption, and the service involves minimal, standardized interactions between staff and customers. We leverage this essential feature of fast-food service provision to undertake an initial test of $\mathrm{H} 2$.

\section{Controls}

In addition to testing the hypothesized relationships, we sought to account for the impact of several other factors that might influence PWYW payments. First, expectations represent prior beliefs, which consumers use to judge product or service quality (Cadotte, Woodruff, and Jenkins 1987; Habel et al. 2016; Zeithaml, Berry, and Parasuraman 1993). Consumers likely rely on their subjective expectations, which in turn might affect their PWYW payment decisions. Second, we account for reciprocity. In line with fairness theory 
(Bolton and Lemon 1999), consumers who pay very little or nothing may experience social pressures if their service relationship is governed by patterns of reciprocity (Heyman and Ariely 2004; Kim, Kaufmann, and Stegemann 2014; Schumann, Wangenheim, and Groene 2014). Third, we control for consumers' preferences for PWYW relative to fixed prices. On the one hand, consumers might sense discomfort when faced with exceptions to accepted norms (i.e., fixed pricing systems) and thus experience distress, self-image concerns, or mental costs in their effort to determine an appropriate price to pay (Ariely, Bracha, and Meier 2009; Gneezy et al. 2012). On the other hand, when consumers set the price, they might enjoy enhanced perceived control, fairness perceptions, and satisfaction (Chandran and Morwitz 2006; Haws and Bearden 2006; Nicolau 2012). Fourth, the degree of customer loyalty similarly may affect PWYW decisions (Kim, Kaufmann, and Stegemann 2014). In the related context of tipping, Lynn and McCall (2000) and Conlin, Lynn, and O’Donoghue (2003) find a significant positive correlation between tip size and loyalty, though other studies indicate no such effect (Kim, Natter, and Spann 2009; Reinartz and Kumar 2002).

\section{Materials and Measures}

The paper menus retrieved from the boxes indicated the dishes the customers chose and the PWYW amounts they were willing to pay for their meals. The survey that customers completed at the end of the meal included questions about the degree to which their expectations were met ("How did the meal compare to your expectations?"), the perceived quality of the meal ("How would you rate the quality of the meal you had?"), and their dispositional tendencies to exhibit positive reciprocity ("Generally, I tend to be nice to people who treat me nicely"). We also measured customers' attitudes toward PWYW ("Would you prefer to have regular prices set by the owner?"), their loyalty (i.e., number of times they had eaten at the restaurant before the start of the PWYW pricing scheme), and 
whether they discussed the payment with other guests at their table. The question about discussing payments with other customers differed slightly between the fast-food and casual restaurant settings. In the fast-food restaurant, customers sit at long tables, in close proximity to strangers, so the question asked, "Have you discussed how much to pay for your meal with others?" instead of "Have you discussed how much to pay for your meal with others at your table?" Appendix A provides a complete list of the survey items. Results

Table 2 contains the descriptive statistics. In the conventional restaurant, approximately the same proportion of customers participated in the before (51\%) and after (49\%) conditions. In the fast-food restaurant, about $54 \%$ of the participants participated in the before condition, and $46 \%$ were in the after condition. On average, customers' deviation from initial expectations did not significantly differ from zero $\left(\mathrm{M}_{\mathrm{conv}}=.10, \mathrm{M}_{\mathrm{fast}}\right.$ $=-.23$ ), and the variability of the deviation from initial expectations was significantly smaller in the fast-food than in the conventional restaurant $(F(1,439)=5.45, p<.01$, Levene's test). That is, the service is significantly less uncertain in the fast-food restaurant. Slightly more than half of the customers (54\%) in the conventional restaurant and $66 \%$ of the customers in the fast-food restaurant reported a preference for regular fixed prices over PWYW pricing.

\section{[INSERT TABLE 2 HERE]}

Table 3 provides the statistics for the variables related to PWYW payments. Across both before and after conditions and restaurants, PWYW payments are substantially higher than $0(p<.01)$. Yet they are significantly lower than regular (fixed menu) prices in the conventional restaurant $(p<.01)$ and only marginally lower in the fast-food restaurant $(p<$ .10). Fewer than $1 \%$ of the guests in the conventional restaurant and slightly more than $2 \%$ in the fast-food setting decided to free ride and pay nothing. 


\section{[INSERT TABLE 3 HERE]}

In the conventional restaurant, customers paid on average $76 \%$ of the regular prices in the before condition but $90 \%$ in the after condition, indicating a significant difference between conditions $(p<.01)$. In the fast-food restaurant, the PWYW payments did not differ significantly across conditions; customers paid $95 \%$ of the regular prices in the before condition and $96 \%$ in the after condition $(p=.48)$. These results support H1 in the conventional restaurant but not in the fast-food restaurant. We also detail this main "before-after" effect in Table 4, by presenting the results of a hierarchical regression analysis with the PWYW amount as the dependent variable.

\section{[INSERT TABLE 4 HERE]}

The explanatory variables in the full regression model include all the variables from Table 2 except quality, which we excluded to avoid issues of multicollinearity, due to its high correlation with expectations $(r=.743, p<.01)$. These regression results confirm that paying for the meal after consumption results in significantly higher PWYW amounts than paying before consumption (Model 1, $p<.01$ ), in further support of H1. Despite an insignificant main effect of uncertainty ( $p=.47$, Model 2; $p=.65$, Model 3), we find a significant interaction between payment timing and uncertainty in the conventional restaurant, such that customers who provided PWYW payments after their consumption in this more uncertain setting paid significantly more than those who paid before $(p<.01$, Model 3), in line with $\mathrm{H} 2$.

Next, introducing additional control variables in the regression analysis clarifies some other determinants of PWYW payments. A positive deviation from initial expectations is a significant determinant of the PWYW amount (Model 3, $p<.05$ ), so customers with better meal experiences paid significantly higher amounts. Payments by customers who scored higher on reciprocity traits also were greater than those from customers with lower levels 
of this trait (Model 3, $p<.05)$. However, loyalty did not influence the amount customers decided to pay (Kim, Natter, and Spann 2009; Reinartz and Kumar 2002). Whether the customers preferred PWYW to regular fixed pricing or discussed payments with others also did not have any significant influence on payment amounts. As expected, we find a consistent, positive relationship between the regular price of the meal and PWYW amounts $(p<.01)$. Of the socio-demographic variables, only age has a marginally significant, positive impact on PWYW amounts ( $p<.1$, Model 3); older customers pay more. Education exerts a marginally significant, negative effect $(p<.1$, Model 3). The adjusted R-squared value indicates that the model explains close to $70 \%$ of the variation in the amounts voluntarily paid to the restaurants.

\section{STUDY 2: DISENTANGLING UNCERTAINTY ABOUT THE SERVICE PROCESS AND SERVICE OUTCOME}

In Study 1, at least three aspects related to uncertainty were confounded. First, in the fast-food restaurant, customers observed the premade food before consumption, which helped reduce uncertainty about the service outcome, that is, the food itself. Second, the service process was less complex, shorter, and much more standardized in the fast-food relative to the conventional restaurant. Third, the "before-after" effect we uncover in Study 1 might stem from the different price ranges and purchase frequencies across the two restaurant contexts. Therefore, in Study 2 we hold the service context constant to identify the role of uncertainty before consumption, as uncertainty about the quality of the food (service outcome) and uncertainty about the experience (service process).

\section{Data Collection, Sample, and Procedures}

This between-subjects study, conducted in July 2017, included 146 participants (average age 24 years, $52 \%$ male) who received payments of 5 Euros each. We presented these participants with a hypothetical PWYW scenario for a restaurant that asked them to 
decide how much they would pay for a specific meal, before service consumption. Specifically, in the scenario, participants were to imagine that they were going out for dinner to a family-owned restaurant and would eat a large starter plate, such as a large Greek salad. By suggesting a single food item, we encouraged these participants to focus on a specific item and avoid the vast price dispersion that could arise from the variety of items and quantity of food that participants could have had in mind. The $2 \times 2$ laboratory experiment varied uncertainty toward the service outcome (visible food/not) and the service process (predictable/volatile). Therefore, in the low uncertainty service outcome condition, participants read that they could see the starter plates in a display: "You can see the starter plates from a display counter. You check out the starter plates in the display and decide the one that you prefer. When you are back at your table, the waiter takes your order and will later bring you the chosen plate together with a bread basket.” In the high uncertainty service outcome condition, they instead could only see the list of dishes on a menu: "You check out the starter plates in the written menu and ask for the one that you prefer. The waiter takes your order and will later bring you the chosen plate together with a bread basket." For the service process manipulation, in the low-uncertainty condition, the restaurant was described as "fairly pleasant and enjoyable on average." The highuncertainty scenario instead stated that "whereas on average the service process in the restaurant is fairly pleasant and enjoyable, on some days it can be excellent and on others it can be rather disappointing." Manipulation checks confirmed that the food quality and service process uncertainty manipulations were perceived as intended. Appendix B presents the complete design, including the post-experimental questionnaire.

Results

The manipulation checks worked as intended. Low/high uncertainty for service outcomes $\left(\mathrm{M}_{\mathrm{LUO}}=3.42, \mathrm{M}_{\mathrm{HUO}}=4.41, p<.01\right)$ and service processes $\left(\mathrm{M}_{\mathrm{LUP}}=5.72, \mathrm{M}_{\mathrm{HUP}}=\right.$ 
$2.44, p<.01)$ were perceived as different, in the expected directions, whereas the level of service outcome (visible food/not) $\left(\mathrm{M}_{\mathrm{Vis}}=3.8, \mathrm{M}_{\mathrm{NVis}}=3.96\right.$, n.s. $)$ and service process (average/volatile) $\left(\mathrm{M}_{\mathrm{Avg}}=4.05, \mathrm{M}_{\mathrm{vol}}=4.02\right.$, n.s. $)$ were not perceived as different across conditions.

We find a significant main effect of service outcome (food) uncertainty on PWYW, such that the mean PWYW amount when food was not visible $(\mathrm{M}=4.87)$ is significantly lower than that when the food is visible $(\mathrm{M}=5.84 ; \mathrm{F}(1,142)=5.839, p<.05)$. According to the significant main effect of uncertainty in the service process, we similarly find that the mean PWYW amount in the predictable service process condition $(\mathrm{M}=5.72)$ is significantly higher than that in the volatile service process condition $(\mathrm{M}=4.97 ; \mathrm{F}(1,142)$ $=3.850, p<.05)$. Furthermore, a significant two-way interaction effect arises, between uncertainty toward the service outcome (food) and uncertainty toward the service process $(\mathrm{F}(1,142)=3.954, p<.05)$. The regular price estimates that participants listed for the food they decided to order, which ranged from hummus to goat cheese, were not significantly different across the between-subjects conditions, according to an analysis of variance (ANOVA; $F(3,142)=1.43, p=.23)$. Thus, the comparison of relative PWYW amounts does not yield significantly different results than the direct comparison. As presented graphically in Figure 2, the mean PWYW amount before consumption is significantly higher when both uncertainty about outcome quality and uncertainty about the service process are low. As a clearer insight into $\mathrm{H} 2$, we thus show that, before a service experience, both outcome and process uncertainty must be low if the goal is to generate higher PWYW amounts.

\section{[INSERT FIGURE 2 HERE]}

Underlining the importance of both service outcomes and service process uncertainty in relation to payment timing effects, this study thus suggests that consumers pay more 
before consumption only when both sources of uncertainty can be resolved. Implementing PWYW after service consumption mostly resolves this uncertainty, because the consumer already has knowledge, prior to paying, about both the service process and the service outcome. These findings in turn might offer practical insights for the strategic designs of sit-down versus fast-food restaurant differences; the service process is central to any dining experience (Lynn and Sturman 2010; Ryu, Lee, and Kim 2012).

\section{STUDY 3: COMPARING THE PROFITABILITY OF PWYW TIMING TO FIXED PAYMENTS AT DIFFERENT LEVELS OF UNCERTAINTY}

In Study 1, we tested how timing and uncertainty affect PWYW amounts and found that, in the presence of uncertainty, consumers pay more after consumption than before. However, we measured uncertainty with a comparison of two different service contexts, which likely differ in other respects too. We also did not investigate the impact on profits, because we lacked information about variable costs, and the PWYW mechanism was not advertised. In Study 2, by holding the service context constant, we provided laboratory evidence that any source of uncertainty can be detrimental for payments before consumption. Yet we still have not established a comparison between before and after payment timing at different levels of uncertainty, nor achieved a valid measure of the effects on profits. Therefore, in Study 3 we directly compare PWYW amounts (before and after consumption) to fixed payments in a service setting by holding the context constant, actively manipulating uncertainty, and analyzing profitability levels across conditions.

\section{Data Collection, Design, and Procedures}

The field study in Study 3 features a cruise company and was conducted during June 2018. As part of its service provision, for each typical journey, the company photographs individuals or groups of passengers as they cross the bridge of the boat and informs them that a high-resolution photo is available at a price of $£ 7$ (approximately $\$ 10$ ). Before 
leaving the boat, passengers can see their photo on a digital display onboard and decide whether to buy it. For this experiment, we manipulated the pricing mechanism (fixed price vs. PWYW) and payment timing on different days. Thus we investigated a fixed $£ 7$ pricing condition; a PWYW before condition, such that passengers had to decide how much to pay for the photo before seeing it; and two PWYW after conditions, in which passengers had to decide whether to buy the photo and how much to pay for it after seeing it on display (after1) or else decided whether to buy it after seeing the display but could wait until after they received the physical photograph to decide how much to pay for it (after2). The PWYW decision entails varying times and levels of uncertainty. Specifically, in the PWYW before condition, passengers made the payment decision before seeing their photo. In PWYW after1, passengers saw their photo on display before making the payment decision; in PWYW after2, their uncertainty was even lower, because they could see exactly how the photo looked in print before making their payment decision. Thus, uncertainty is the highest in the PWYW before condition and lowest in the PWYW after2 condition.

We alternated the four conditions daily over four weeks (28 days), such that each condition was implemented for 7 days. Consistent with Study 1, we did not provide any information about the fixed price to serve as a reference price in the PWYW conditions. During the four-week study period, 2,666 passengers travelled with the company. We collected data about paid prices, number of total passengers, number of passengers who decided to buy photos, and unit variable costs for the company (£2.55), which we use to establish managerial insights regarding the profitability of the PWYW mechanism. Furthermore, we collected data about passengers' average spending on food and drinks purchased from an onboard service, which we use to check whether differences in the average cruise prices reflect influences of the days or weeks when the interventions 
occurred. Our main focus is the proportion of total passengers who bought the photo, such that we isolates possible spillover effects that might have affected the overall use of the service (i.e., total passengers) and we can offer clear evidence on service capacity utilization.

Results

Table 5 summarizes the average price paid, variable costs, percentage of passengers who chose to buy photos, and unit profit for each condition. We calculated unit profit by multiplying individual margin (price paid minus unit variable cost) for those passengers who chose to buy the photos, as a proportion of the total number of passengers.

\section{[INSERT TABLE 5 HERE]}

The ANOVA of prices yielded significant variation across conditions $(F(3,850)=$ 24.58, $p<.001)$. According to a post hoc Tukey test, compared with the fixed price, the PWYW before amounts are significantly lower $(p<.01)$. We also note a significant price difference between PWYW after1 and PWYW after2 $(p<.05)$, such that PWYW after2 generates higher payments. The fixed price isn't statistically different from either the after1 or the after2 average though. With chi-square tests, we determine whether the number of passengers who decided to purchase the photo is significantly higher in the PWYW conditions, which speaks for service capacity utilization considerations. We find no significant difference between the fixed price and PWYW before conditions, but in the PWYW after1 $\left(\chi^{2}(1, \mathrm{~N}=1360)=10.35, p=.001\right)$ and PWYW after2 $\left(\chi^{2}(1, \mathrm{~N}=1355)=\right.$ $17.0, p<.001)$ conditions, purchases increase relative to the fixed price condition. In terms of profitability, an ANOVA of unit profit yielded significant variation $(F(3,850)=45.24, p$ $<.001)$. Post hoc Tukey tests indicate that the unit profit is lower in the PWYW before condition than in the fixed price setting $(p<.01)$. However, PWYW after1 produces higher profits than the fixed price condition $(p<.05)$, and this effect is stronger for PWYW after2 
$(p<.01)$. Profitability is significantly higher in after 2 than in after $1(p<.01)$, which suggests that reducing uncertainty even further paid off, in profitability terms. With regard to the potential confounds that we measured, we observe no significant differences in the total number of passengers or in the average amount spent on coffee and snacks onboard across the four conditions or across the different weeks of the experiment.

\section{GENERAL DISCUSSION}

To the best of our knowledge, these studies are the first to systematically examine the role of timing of the PWYW mechanism and to offer insights on conditions that ensure its profitability relative to fixed prices at different levels of uncertainty. Within an uncertainty reduction framework, we establish that PWYW can be profitable, compared with fixed prices, if customers pay for the service after consumption and the business reduces their uncertainty about the service process and service outcome. These results hold even when we control for other PWYW determinants, such as expectations, reciprocity, and loyalty (Kim, Kaufmann, and Stegemann 2014; Schmidt, Spann, and Zeithammer 2015).

In a conventional restaurant setting, we show that the PWYW amount is about $18 \%$ higher (10.84 vs. 12.83) when the payment decision takes place after consumption, compared with before. In addition, uncertainty moderates this before-after difference. Study 2 unpacks this uncertainty effect by considering both uncertainty toward the service process and uncertainty toward the service outcome and thus further explicates PWYW behaviors before consumption. Finally, the last field experiment (Study 3) addresses profitability questions by comparing before-after PWYW effects against fixed prices and manipulating uncertainty across two different after consumption conditions. With this study, we also tested several actionable managerial interventions and complement the initial evidence from the restaurant experiment. In particular, finding ways to reduce uncertainty after consumption can produce profitability levels that surpass those of a fixed 
price mechanism. The introduction of the PWYW mechanism after consumption also increased the number of customers (see also Gneezy et al. 2010; Riener and Traxler 2012) and resulted in a positive effect on total revenues and profits, mainly due to increased service capacity utilization.

\section{Theoretical Implications}

Our results address some lingering questions in both PWYW research and more general pricing and service literature. First, we offer an explanation for conflicting findings regarding the profitability of PWYW pricing (Kim, Natter, and Spann 2009; Gneezy et al. 2010; Stangl and Prayag, 2018) by introducing payment timing as an important contingency factor. Three studies show consistently that paying after consumption increases PWYW amounts, compared with paying before consumption. The difference between paying before and after consumption is especially relevant in settings characterized by high service process and service outcome uncertainty, such as in conventional restaurants or photography services during a cruise.

Second, we establish some boundary conditions for the profitability of PWYW (before and after consumption), which represents a direct response to Spann et al.'s (2018) call for research that assesses how payment timing affects buyers' behavior and thus sellers' profitability. Our findings show that letting customers pay after consumption, while also reducing uncertainty through other means, has a positive effect on profitability, compared with a fixed price mechanism, primarily due to an increased service capacity utilization (Ng, Wirtz, and Lee 1999; Wirtz and Zeithaml 2018). In other words, PWYW stimulates demand so that, even if customers pay slightly less, the company is better off.

Third, we explicate some of the dynamics that determine consumers' service experiences and perceptions (Bolton and Lemon 1999; Bolton, Lemon, and Bramlett 2006; Iyengar, Ansari, and Gupta 2007; Rust et al. 1999) and further demonstrate that consumers' 
service evaluations directly affect the amount they are willing to pay. In this sense, we affirm the importance of uncertainty reduction efforts. That is, prior research indicates that uncertainty reduction prior to consumption can motivate consumers to choose less optimal pricing schemes (Lambrecht and Skiera 2006) or seek providers that offer service guarantees (Hogreve and Gremler 2009). We also establish that service providers can benefit from the positive effects of uncertainty reduction after consumption, with positive effects on average payments and customer acquisition.

\section{Managerial Implications}

The empirical evidence, showing that PWYW can be a promising mechanism for service providers, also suggests three main implications for service managers. First, service managers implementing a PWYW pricing scheme should ask consumers to pay after their service experience. The evidence gathered from real-world applications of PWYW (Table 1) indicates a consistent success pattern: PWYW fails when its implementation demands that customers pay before consumption.

Second, service managers should actively work to reduce uncertainty about the service process and the service outcome. Recent research on the interplay between pain (e.g., paying) and pleasure (e.g., enjoying the service) suggests that offering an upfront service guarantee might not help, especially for consumers with promotion concerns (Liu, Mattila, and Bolton 2018). In our studies, even for payments made after consumption, reducing uncertainty as much as possible offers a promising path toward profitability. These findings resonate with examples in practice, such as Lyft's unsuccessful experiment with PWYW, in which the company requested payment from riders before they consumed the technology-based service. Our findings indicate that Lyft might have been more successful if it had sought payment after the consumption, so that riders had the chance to experience 
the service quality (e.g., punctuality, drivers' performance, technologically enhanced GPS features) and enjoy reduced uncertainty levels before making their payment decisions.

Third, the profitability comparison between PWYW and a fixed price strategy reveals that implementing PWYW after service consumption increases service capacity utilization, counterbalancing the possible effect of lower individual price contributions. By demonstrating this effect across different contexts, we support the generalizability of the profitability of the PWYW mechanism, beyond hospitality fields (Mattila and Gao 2016), for services with clear before-after uncertainty reduction effects, which also might include repair, hair styling, copy-editing, and cleaning services.

\section{Limitations and Directions for Research}

In Study 1, we could not completely tease out the number of customers who accessed the service or offer a well-defined profitability assessment, due to the difficulty of retrieving exact cost figures. Such confines are inherent to field studies (Gneezy 2017); we addressed them in the laboratory study (Study 2) and, in terms of profitability, in the last field experiment (Study 3). These more controlled settings show that the effect of uncertainty reduction is robust to the number of customers, price levels, and purchase frequency.

Study 2 experimentally induced high or low service process and service outcome uncertainty. Additional research could address other sources of uncertainty, such as unknown relative performance in comparison with similar services (Liu et al. 2015). Although previous research indicates that pricing behaviors transcend national borders and depend mainly on service quality and type (Bolton and Myers 2003), the role of culture and uncertainty avoidance levels in PWYW domains also might be explored further.

Finally, we call for research into the applicability of PWYW in online settings. Clever PWYW applications, combined with effective prompts, potentially could improve the 
revenue positions of online firms, such as news providers, that struggle to maintain their profitability with business models that provide substantial services (e.g., content) for free (Franklin 2014). Online service platforms might increase demand by leveraging PWYW, but doing so creates the challenge that, once consumers have used the service for free, they may resist entering into any sort of payment process. The anonymous online setting also eliminates any potential social pressures or embarrassment about offering no payment to a frontline service employee who has provided a service. Furthermore, some e-services, such as apps and music, feature ongoing usage, so there is no clear "after" consumption point. Yet other online domains promise appealing PWYW potential, such as those that support the sharing economy. In particular, PWYW appears promising when the service entails some form of human connection between the consumer and the provider. 


\section{REFERENCES}

Akdeniz, M. Billur, Roger J. Calantone, and Clay M. Voorhees (2014), "Signaling Quality: an Examination of the Effects of Marketing-and Nonmarketing-Controlled Signals on Perceptions of Automotive Brand Quality," Journal of Product Innovation Management, 31 (4), 728-743.

Ariely, Dan, Anat Bracha, and Stephan Meier (2009), "Doing Good or Doing Well? Image Motivation and Monetary Incentives in Behaving Prosocially," American Economic Review, 99 (1), 544-55.

Bolton, Ruth N., and Katherine N. Lemon (1999), "A Dynamic Model of Customers' Usage of Services: Usage as an Antecedent and Consequence of Satisfaction." Journal of Marketing Research, 36 (2), 171-186.

Bolton, Ruth N., Katherine N. Lemon, and Matthew D. Bramlett (2006), "The Effect of Service Experiences over Time on a Supplier's Retention of Business Customers." Management Science, 52 (12), 1811-1823.

Bolton, Ruth N., and Matthew B. Myers (2003), "Price-based Global Market Segmentation for Services." Journal of Marketing, 67 (3), 108-128.

Cadotte, Ernest R., Robert B. Woodruff, and Roger L. Jenkins (1987), "Expectations and Norms in Models of Consumer Satisfaction," Journal of Marketing Research, 24 (3), 305-314.

Chandran, Sucharita, and Vicki G. Morwitz (2006), "The Price of "Free"-dom: Consumer Sensitivity to Promotions with Negative Contextual Influences," Journal of Consumer Research, 33 (3), 384-392.

Chao, Yong, Jose Fernandez, and Babu Nahata (2015), "Pay-What-You-Want Pricing: Can it be Profitable?," Journal of Behavioral and Experimental Economics, 57, 176-185. 
Conlin, Michael, Michael Lynn, and Ted O’Donoghue (2003), "The Norm of Restaurant Tipping," Journal of Economic Behavior \& Organization, 52 (3), 297-321.

De Pillis, L. (2017), Panera's Pay-As-You-Go Pricing Experiment Failed. Here's how They could Fix it. [online] The Washington Post. Available at: https://www.washingtonpost.com/news/wonk/wp/2013/07/14/down-with-pricetags-heres-how-to-profit-when-people-pay-what-theywant/?utm_term=.dbe276847e34 [Accessed 26 Nov. 2017].

Franklin, Robert (2014), "The Future of Journalism: in an Age of Digital Media and Economic Uncertainty," Journalism Studies, 15 (5), 481-499.

Gneezy, Ayelet (2017), "Field Experimentation in Marketing Research." Journal of Marketing Research 54 (1), 140-143.

Gneezy, Ayelet, Uri Gneezy, Leif D. Nelson, and Amber Brown (2010), "Shared Social Responsibility: A Field Experiment in Pay-What-You-Want Pricing and Charitable Giving," Science, 329 (5989), 325-327.

Gneezy, Ayelet, Uri Gneezy, Gerhard Riener, and Leif D. Nelson (2012), "Pay-What-YouWant, Identity, and Self-Signaling in Markets," Proceedings of the National Academy of Sciences, 109 (19), 7236-7240.

Habel, Johannes, Sascha Alavi, Christian Schmitz, Janina-Vanessa Schneider, and Jan Wieseke (2016), "When Do Customers Get What They Expect? Understanding the Ambivalent Effects of Customers' Service Expectations on Satisfaction," Journal of Service Research, 19 (4), 361-379.

Haws, Kelly L., and William O. Bearden (2006), "Dynamic Pricing and Consumer Fairness Perceptions," Journal of Consumer Research, 33 (3), 304-311.

Heyman, James, and Dan Ariely (2004), "Effort for Payment: A Tale of Two Markets," Psychological science, 15 (11), 787-793. 
Hogreve, Jens, and Dwayne D. Gremler (2009), "Twenty Years of Service Guarantee Research: A Synthesis," Journal of Service Research, 11 (4), 322-343.

Humble Bundle (2018), "Humble Bundle," [online] Available at: https://www.humblebundle.com/ [Accessed 24 Apr. 2018].

Iyengar, Raghuram, Asim Ansari, and Sunil Gupta (2007), "A Model of Consumer Learning for Service Quality and Usage," Journal of Marketing Research, 44 (4), $529-544$.

Jang, Hyunkyu, and Wujin Chu (2012), "Are Consumers Acting Fairly Toward Companies? An Examination of Pay-What-You-Want Pricing," Journal of Macromarketing, 32 (4), 348-360.

Jerger, Christina, and Jochen Wirtz (2017), "Service Employee Responses to Angry Customer Complaints: The Roles of Customer Status and Service Climate," Journal of Service Research, 20 (4), 362-378.

Johnson, Jennifer Wiggins, and Annie Peng Cui (2013), "To Influence or Not to Influence: External Reference Price Strategies in Pay-What-You-Want Pricing," Journal of Business Research, 66 (2), 275-281.

Kim, Ju-Young, Katharina Kaufmann, and Manuel Stegemann (2014), "The Impact of Buyer-Seller Relationships and Reference Prices on the Effectiveness of the Pay What you Want Pricing Mechanism," Marketing Letters, 25 (4), 409-423.

Kim, Ju-Young, Martin Natter, and Martin Spann (2009), "Pay What You Want: A New Participative Pricing Mechanism," Journal of Marketing, 73 (1), 44-58.

Kim, Ju-Young, Martin Natter, and Martin Spann (2010), "Kish: Where Customers Pay as They Wish," Review of Marketing Science, 8 (2).

Kunter, Marcus (2015), "Exploring the pay-what-you-want payment motivation," Journal of Business Research, 68 (11), 2347-2357. 
Lambrecht, Anja, and Bernd Skiera (2006), "Paying Too Much and Being Happy about it: Existence, Causes, and Consequences of Tariff-choice Biases," Journal of Marketing Research, 43 (2), 212-223.

León, Francisco J., José A. Noguera, and Jordi Tena-Sánchez (2012), "How Much Would You Like to Pay? Trust, Reciprocity and Prosocial Motivations in El Trato," Social Science Information, 51 (3), 389-417.

Liu, Stephanie Q., Anna S. Mattila, and Lisa E. Bolton (2018), "Selling Painful Yet Pleasurable Service Offerings: An Examination of Hedonic Appeals." Journal of Service Research, 1094670518770044.

Liu, Yeyi, Andreas B. Eisingerich, Seigyoung Auh, Omar Merlo, and Hae Eun Helen Chun (2015), "Service Firm Performance Transparency: How, When, and Why does it Pay Off?," Journal of Service Research, 18 (4), 451-467.

Lynn, Michael, and Michael McCall (2000), "Gratitude and Gratuity: a Meta-analysis of Research on the Service-Tipping Relationship," The Journal of Socio-Economics, 29 (2), 203-214.

Lynn, Michael, and Michael Sturman (2010), "Tipping and Service Quality: a WithinSubjects Analysis," Journal of Hospitality \& Tourism Research, 34 (2), 269-275. Mattila, Anna S., and Cathy A. Enz (2002), "The Role of Emotions in Service Encounters," Journal of Service Research, 4 (4), 268-277.

Mattila, Anna S., and Yixing Gao (2016), "An Examination of Popular Pricing and Price Framing Techniques in the Hospitality Industry and Directions for Future Research," International Journal of Revenue Management, 9 (2-3), 175-185.

Moeller, Sabine (2010), "Characteristics of Services-a New Approach Uncovers their Value," Journal of Services Marketing, 24 (5), 359-368. 
Murray, Keith B. (1991), "A Test of Services Marketing Theory: Consumer Information Acquisition Activities," The Journal of Marketing, 55 (1), 10-25.

Ng, Irene CL, Jochen Wirtz, and Khai Sheang Lee. (1999), "The Strategic Role of Unused Service Capacity." International Journal of Service Industry Management, 10 (2), 211-244.

Nicolau, J. L. (2012), "Battle Royal: Zero-price Effect vs Relative vs Referent Thinking," Marketing Letters, 23 (3), 661-669.

Oliver, Richard L. (1980), "A Cognitive Model of the Antecedents and Consequences of Satisfaction Decisions," Journal of Marketing Research, 17 (4), 460-469.

Papakonstantinou, Athanasios, and Peter Bogetoft (2017), "Multi-dimensional Procurement Auction under Uncertain and Asymmetric Information," European Journal of Operational Research, 258 (3), 1171-1180.

Parasuraman, Anantharanthan, Valarie A. Zeithaml, and Leonard L. Berry (1985), "A Conceptual Model of Service Quality and its Implications for Future Research," The Journal of Marketing, 49 (4), 41-50.

Pay What You Want IBIS. (2015). Retrieved 7 October 2015, from http://ibispaywhatyouwant.co.in/

Regner, Tobias, and Javier A. Barria (2009), "Do Consumers Pay Voluntarily? The Case of Online Music," Journal of Economic Behavior \& Organization, 71 (2), 395-406. Reinartz, Werner, and Viswanathan Kumar (2002), "The Mismanagement of Customer Loyalty," Harvard business review, 80 (7), 86-95.

Riener, Gerhard, and Christian Traxler (2012), "Norms, Moods, and Free Lunch: Longitudinal Evidence on Payments from a Pay-What-You-Want Restaurant," The Journal of Socio-Economics, 41 (4), 476-483. 
Rust, Roland T., J. Jeffrey Inman, Jianmin Jia, and Anthony Zahorik (1999), "What You Don't Know about Customer-perceived Quality: The Role of Customer Expectation Distributions," Marketing Science 18 (1), 77-92.

Ryu, Kisang, Hye-Rin Lee, and Woo Gon Kim (2012), "The Influence of the Quality of the Physical Environment, Food, and Service on Restaurant Image, Customer Perceived value, Customer Satisfaction, and Behavioral Intentions," International Journal of Contemporary Hospitality Management, 24 (2), 200-223.

Schmidt, Klaus M., Martin Spann, and Robert Zeithammer (2015), "Pay What You Want as a Marketing Strategy in Monopolistic and Competitive Markets," Management Science, 61 (6), 1217-1236.

Schumann, Jan H., Florian von Wangenheim, and Nicole Groene (2014), "Targeted Online Advertising: Using Reciprocity Appeals to Increase Acceptance Among Users of Free Web Services, " Journal of Marketing, 78 (1), 59-75.

Shugan, Steven M., and Jinhong Xie. (2000), "Advance Pricing of Services and Other Implications of Separating Purchase and Consumption," Journal of Service Research, 2 (3), 227-239.

Spann, Martin, Robert Zeithammer, Marco Bertini, Ernan Haruvy, Sandy D. Jap, Oded Koenigsberg, Vincent Mak, Peter Popkowski Leszczyc, Bernd Skiera, and Manoj Thomas (2018), "Beyond Posted Prices: the Past, Present, and Future of Participative Pricing Mechanisms," Customer Needs and Solutions, 5 (1), 121-136.

Stangl, Brigitte, and Girish Prayag (2018), "Collaborative Destination Marketing and PWYW," Annals of Tourism Research, 70 (1), 103-104.

Thompson, Gary M. (2015), "Deciding Whether to Offer "Early-bird" or "Night-owl" Specials in Restaurants: A Cross-functional View," Journal of Service Research, 18 (4), 498-512. 
Weisstein, Fei L., Monika Kukar-Kinney, and Kent B. Monroe (2016), "Determinants of Consumers' Response to Pay-What-You-Want Pricing Strategy on the Internet," Journal of Business Research 69 (10), 4313-4320.

Wirtz, Jochen, and Valarie Zeithaml (2018), "Cost-effective Service Excellence." Journal of the Academy of Marketing Science, 46 (1), 59-80.

Zeithaml, Valarie A., Leonard L. Berry, and Arantharanthan Parasuraman (1993), "The Nature and Determinants of Customer Expectations of Service," Journal of the academy of Marketing Science, 21 (1), 1-12. 
Table 1. Notable Industry Applications of PWYW, Before or After Consumption

\begin{tabular}{|c|c|c|}
\hline Company & Before/After & Key Findings \\
\hline Der Wiener Restaurant & $\begin{array}{l}\text { After (Riener and } \\
\text { Traxler 2012) }\end{array}$ & $\begin{array}{l}\text { Implemented in } 2010 \text { and still in use (though not every } \\
\text { night); prices are slightly lower than regular prices, but the } \\
\text { pricing scheme remains sustainable in terms of } \\
\text { profitability. }\end{array}$ \\
\hline $\begin{array}{c}\text { French restaurant and } \\
\text { cafeteria in Munster } \\
\text { (Germany) }\end{array}$ & $\begin{array}{l}\text { Before (Kim, } \\
\text { Kaufmann, and } \\
\text { Stegemann 2014) } \\
\end{array}$ & $\begin{array}{l}\text { Payments differ significantly from zero but are relatively } \\
\text { lower than traditional pricing. }\end{array}$ \\
\hline $\begin{array}{l}\text { Holiday Package "El } \\
\text { trato" }\end{array}$ & $\begin{array}{l}\text { Before (León, Nogura, } \\
\text { and Tena-Sanchez, } \\
\text { 2012) }\end{array}$ & $\begin{array}{l}\text { Prices paid are significantly below the price under a } \\
\text { regular pricing mechanism; the mechanism stopped. }\end{array}$ \\
\hline $\begin{array}{l}\text { Humble Bundle (digital } \\
\text { distribution) }\end{array}$ & $\begin{array}{l}\text { Before (Humble } \\
\text { Bundle 2018) }\end{array}$ & $\begin{array}{l}\text { In place since } 2009 \text {, with good profitability. Raising } \\
\text { money for charity is the core mission. }\end{array}$ \\
\hline Ibis Hotels & $\begin{array}{l}\text { After (Pay-What-You- } \\
\text { Want IBIS 2015) }\end{array}$ & $\begin{array}{l}\text { Promotional tool for a month in the Delhi airport hotel. } \\
\text { Increased occupancy for the hotel with mixed effects on } \\
\text { profitability. }\end{array}$ \\
\hline $\begin{array}{l}\text { Large U.S. amusement } \\
\text { park }\end{array}$ & $\begin{array}{l}\text { Before (Gneezy et al. } \\
\text { 2010) }\end{array}$ & $\begin{array}{l}\text { Profitable only when combined with a charitable giving } \\
\text { component. }\end{array}$ \\
\hline Lyft (car ride company) & Before (De Pillis 2017) & Discontinued due to poor profitability. \\
\hline $\begin{array}{l}\text { Multiplex cinema near } \\
\text { Frankfurt }\end{array}$ & $\begin{array}{l}\text { Before (Kim, Natter, } \\
\text { and Spann 2009) }\end{array}$ & Price paid was significantly below regular pricing. \\
\hline Panera Bread & Before (DePillis 2017) & Stopped because profit performance was not satisfactory. \\
\hline $\begin{array}{l}\text { Persian restaurant in } \\
\text { Frankfurt and } \\
\text { delicatessen in } \\
\text { Wiesbaden }\end{array}$ & $\begin{array}{l}\text { After (Kim, Natter, } \\
\text { and Spann 2009) }\end{array}$ & $\begin{array}{l}\text { The price paid was very close }(80 \%-90 \%) \text { to the regular } \\
\text { price; mechanism is still in place. }\end{array}$ \\
\hline $\begin{array}{l}\text { Surgery Journal (Taylor } \\
\quad \text { \& Francis) }\end{array}$ & $\begin{array}{l}\text { After (Spann et al. } \\
\text { 2018) }\end{array}$ & $\begin{array}{l}\text { Very high variability in payments under PWYW, with a } \\
\text { significant proportion of payments above the regular } \\
\text { price. The mechanism is still in place. }\end{array}$ \\
\hline
\end{tabular}


Table 2. Descriptive Statistics $(n=296$ in conventional, $n=145$ in fast-food)

\begin{tabular}{l|l|cc|cc}
\hline \multicolumn{2}{l|}{} & \multicolumn{2}{c|}{ Conventional } & \multicolumn{2}{c}{ Fast-Food } \\
\hline Variable & Variable Description & Mean & St.Dev. & Mean & St.Dev. \\
\hline PayTiming & Payment after (=1) or before (=0) consumption & 0.49 & 0.50 & 0.46 & 0.50 \\
Expectations & Deviation from initial expectations (-3 to 3) & 0.10 & 1.24 & -0.23 & 0.95 \\
PosRec & Dispositional positive reciprocity (0-10) & 7.54 & 1.24 & 7.17 & 1.54 \\
Regular Better & Preference for fixed prices (=1) or PWYW (=0) & 0.54 & 0.50 & 0.66 & 0.48 \\
Loyalty & Having been more than 5 times (=1) or equal or less & 0.34 & 0.47 & 0.44 & 0.50 \\
& than 5 times (=0) at the restaurant before PWYW & & & & \\
Quality & Perceived meal quality (0-10) & 6.32 & 1.18 & 5.54 & 1.48 \\
Regular Price & Average payment implied by the fixed-menu prices & 14.22 & 5.32 & 3.41 & 1.39 \\
Dinner & Dinner (=1) or lunch (=0) meal & 0.49 & 0.50 & & \\
Discussion & Discussed payments with other guests at the table & 0.82 & 0.38 & 0.47 & 0.50 \\
& (=1) or not (=0) & & & & \\
Guests & Average number of guests per table (in a party) & 3.11 & 1.44 & 1.65 & 0.83 \\
Age & Age of guests & 0.44 & 0.50 & 0.41 & 0.49 \\
Gender & Female (=1) or male (=0) & 2.64 & 0.86 & 1.85 & 0.70 \\
Education & Level of education in ascending order (1-4) & & & &
\end{tabular}


Table 3. PWYW Payments and Preferences by Condition

\begin{tabular}{lccc|cccc}
\hline & \multicolumn{3}{c|}{ Conventional } & \multicolumn{3}{c}{ Fast-food } \\
\hline Variable & Before & After & $\begin{array}{c}\text { Test of } \\
\text { Difference }\end{array}$ & Before & After & $\begin{array}{c}\text { Test of } \\
\text { Difference }\end{array}$ \\
\hline PWYW & 10.84 & 12.83 & $* * *$ & 3.04 & 3.07 & n.s. \\
Regular Price & 14.20 & 14.24 & n.s. & 3.39 & 3.43 & n.s. \\
PWYW/Regular Price & 0.76 & 0.90 & $* * *$ & 0.95 & 0.96 & n.s. \\
Regular Better & 0.59 & 0.50 & $* *$ & 0.64 & 0.67 & n.s. \\
\hline
\end{tabular}

*** $p<.01, * * p<.05, * p<.1$, two-tailed Mann-Whitney tests.

Notes: Prices are in Euros; PWYW is the average individual payment under the pay-what-you-want pricing mechanism. 
Table 4. Regression Analysis

\begin{tabular}{lrrr}
\hline & \multicolumn{1}{c}{$(1)$} & \multicolumn{1}{c}{$(2)$} & \multicolumn{1}{c}{$(3)$} \\
Dependent Variable & PWYW & PWYW & \multicolumn{1}{c}{ PWYW } \\
\hline PayTiming (After=1) & $1.464^{* * *}$ & $1.455^{* * *}$ & 0.047 \\
& $(0.357)$ & $(0.361)$ & $(0.231)$ \\
Uncertainty & & 0.551 & -0.374 \\
(Conventional=1) & & $(0.768)$ & $(0.831)$ \\
PayTiming*Uncertainty & & & $2.097 * * *$ \\
& & & $(0.556)$ \\
Expectations & $0.419^{*}$ & $0.429 *$ & $0.455^{* *}$ \\
& $(0.220)$ & $(0.220)$ & $(0.221)$ \\
Reciprocity & $0.268^{*}$ & $0.265^{*}$ & $0.279 * *$ \\
& $(0.136)$ & $(0.138)$ & $(0.136)$ \\
Regular Price better & 0.408 & 0.445 & 0.505 \\
& $(0.377)$ & $(0.389)$ & $(0.383)$ \\
Loyalty & 0.276 & 0.265 & 0.199 \\
& $(0.371)$ & $(0.371)$ & $(0.363)$ \\
Regular price & $0.727 * * *$ & $0.704 * * *$ & $0.701 * * *$ \\
& $(0.039)$ & $(0.054)$ & $(0.054)$ \\
Discussion w/others & 0.437 & 0.367 & 0.401 \\
& $(0.307)$ & $(0.311)$ & $(0.310)$ \\
Age & $0.056^{* * *}$ & $0.046 *$ & $0.043 *$ \\
& $(0.017)$ & $(0.025)$ & $(0.025)$ \\
Gender & 0.339 & 0.334 & 0.305 \\
& $(0.365)$ & $(0.367)$ & $(0.364)$ \\
Education & -0.391 & $-0.416^{*}$ & $-0.417 *$ \\
& $(0.240)$ & $(0.250)$ & $(0.248)$ \\
Constant & $-4.960^{* * *}$ & $-4.688^{* *}$ & $-4.174 * *$ \\
& $(1.748)$ & $(1.938)$ & $(1.862)$ \\
Observations & 438 & 438 & 438 \\
R-squared & 0.671 & 0.671 & 0.677 \\
\hline
\end{tabular}

Notes: Standard errors are in parentheses, clustered at the individual level.

$* * * p<.01, * * p<.05, * p<.1$. 
Table 5. Payments, Costs, and Profitability by Condition

\begin{tabular}{lcccc}
\hline Variable & Fixed price & PWYW Before & $\begin{array}{c}\text { PWYW After1 } \\
\text { Lower certainty }\end{array}$ & $\begin{array}{c}\text { PWYW After2 } \\
\text { Higher certainty }\end{array}$ \\
\hline Average price paid & & & $6.61(2.87)$ & $7.22(3.19)$ \\
Unit variable cost & $7(0)$ & $5.25(2.51)$ & 2.55 & 2.55 \\
Purchase rate $^{\mathrm{a}}$ & 2.55 & 2.55 & $34.5 \%$ & $36.8 \%$ \\
Unit profit per purchase rate $^{\mathrm{b}}$ & $26.5 \%$ & $30.6 \%$ & 1.40 & 1.72 \\
\hline
\end{tabular}

Notes: Standard deviations are in parentheses. Prices and profits are in Pounds.

a Purchase rate is calculated by dividing the number of customers who purchased the photo by the total number of customers.

${ }^{\mathrm{b}}$ Unit profit per purchase rate is obtained by multiplying the individual margin (price paid minus unit variable cost) by the purchase rate. 
Figure 1. Conceptual Framework

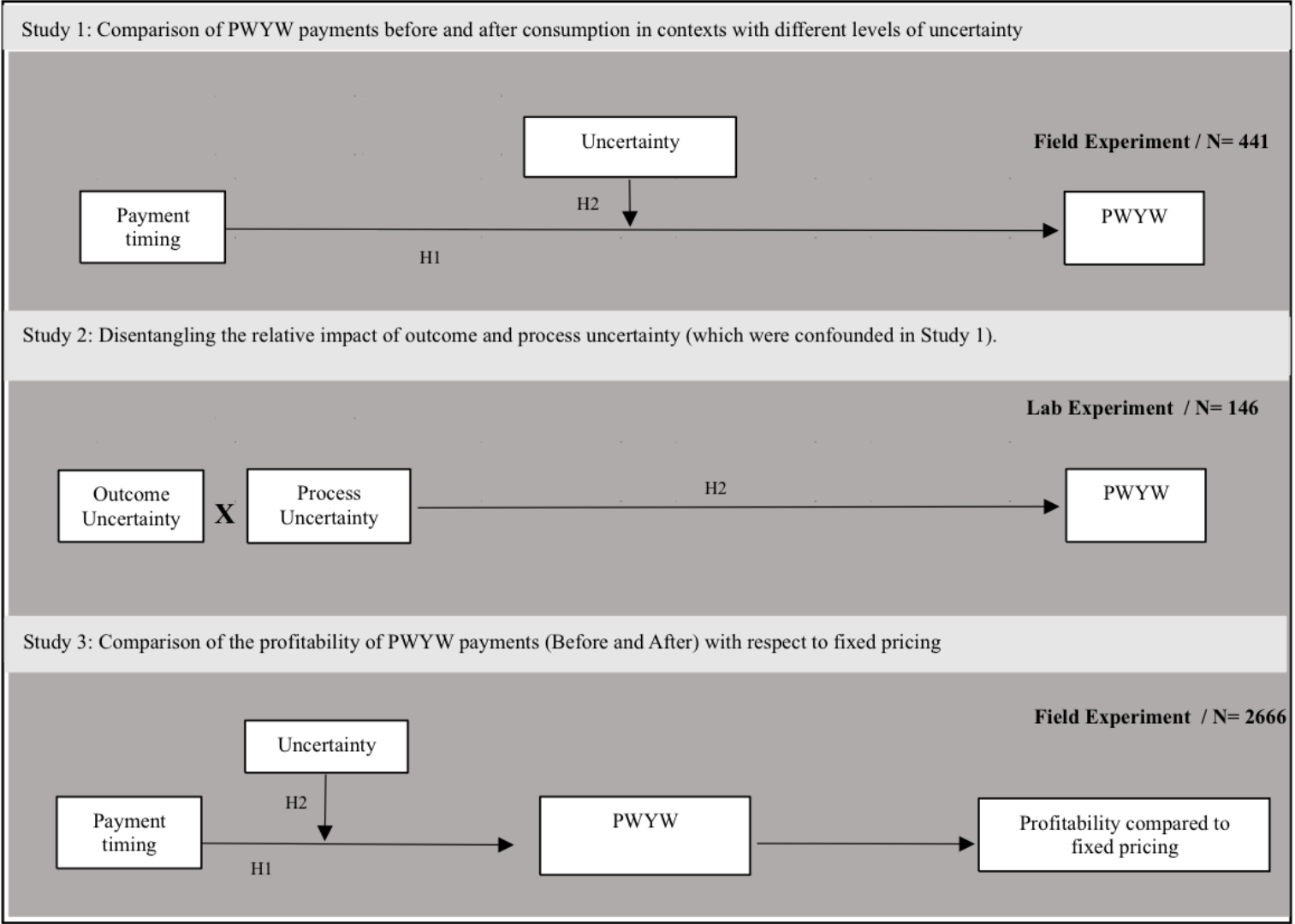


Figure 2. PWYW Payments across Uncertainty Conditions (Study 2)

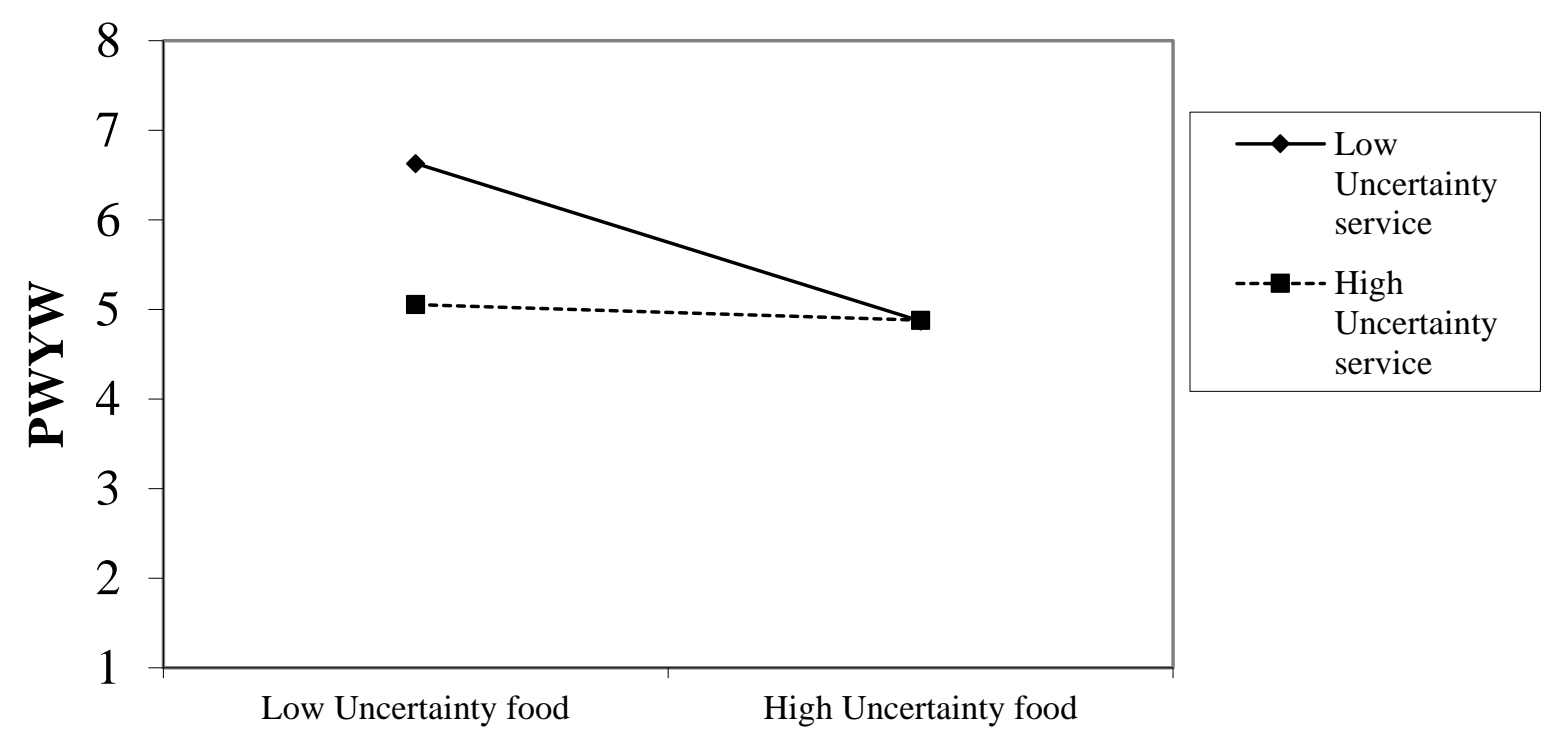

Notes: PWYW prices on the Y-axis are in Euros. 


\section{" Customer Survey}

1) How many times have you eaten at "— before we introduced our new pricing scheme? $\square$ Never $\square$ 1-5 times $\square$ 6-10 times $\square$ more than 10 times

2) How would you rate the quality of the meal you had:

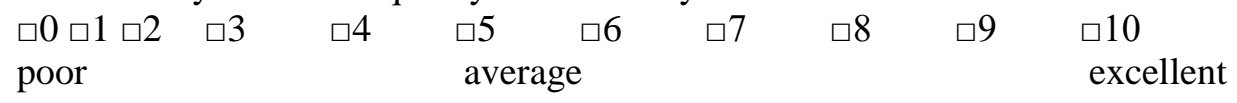

3) How did the meal compare to your expectations?

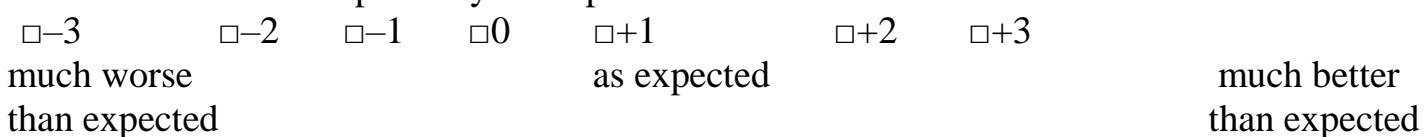

4) Have you been to " $\square$ No since we introduced the Pay-What-You-Want scheme? If yes, how many times?

5) Did you know about the pricing scheme of " before coming? $\square$ Yes $\square$ No

6) Would you prefer to have regular prices set by the owner? $\square$ Yes $\square$ No Any comments

7) Estimate the total cost of the meal you had today: $€$

8) How much do you think you would have paid for your meal today if the owner set the prices? $€$

9) Have you discussed how much to pay for your meal with others at your table? $\square$ Yes $\square$ No

10) Generally, I tend to respond badly to people who treat me unfairly or try to take advantage of me.

$\begin{array}{ccccccccccc}\square 0 & \square 1 & \square 2 & \square 3 & \square 4 & \square 5 & \square 6 & \square 7 & \square 8 & \square 9 & \square 10 \\ \begin{array}{c}\text { Strongly Strongly } \\ \text { disagree }\end{array} & & & & & \end{array}$

11) Generally, I tend to be nice to people who treat me nicely.

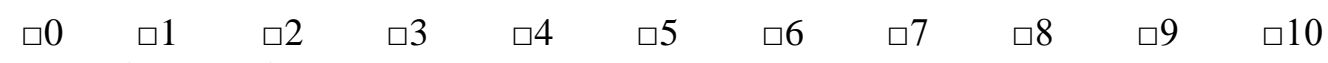

Strongly Strongly

disagree

agree

12) Age:

13) Gender: $\quad \square \mathrm{M} \quad \square \mathrm{F}$

14) Place of residence: $\square$ This city $\square$ Other:

15) Education: $\quad \square$ Less than high school degree $\square$ High school degree

$\square$ Bachelor degree $\quad \square$ Graduate degree 


\section{APPENDIX B - STUDY 2}

\section{(High-Low Uncertainty Food $) \times($ High-Low Uncertainty Process $)$ between-subjects design}

In the next screens you will be presented with a hypothetical scenario related to eating out at restaurants. Please read carefully and try to imagine that you are in the described situations. Respond as truthfully as you can based on the information provided.

\section{Scenario 1 (low process-low food uncertainty):}

Imagine that you go out for dinner to a family-owned restaurant of an average price range in your town or city.

You have heard that the service process in the restaurant in terms of friendliness, waiting time and atmosphere is generally fairly pleasant and enjoyable.

You are not very hungry and simply want to eat a large starter plate, such as a large Greek salad. The waiter presents you with a menu of freshly prepared starter plates and says that you can see the starter plates from a display counter. You check out the starter plates in the display and decide the one that you prefer. When you are back at your table, the waiter takes your order and will later bring you the chosen plate together with a bread basket.

The restaurant is running a new pricing mechanism in which you are entirely free to decide how much you want to pay for the meal (including zero). You have to make your payment decision BEFORE you have your meal.

Based on this description, what is the amount you would decide to pay?

\section{Scenario 2 (low process-high food uncertainty):}

Imagine that you go out for dinner to a family-owned restaurant of an average price range in your town or city.

You have heard that the service process in the restaurant in terms of friendliness, waiting time and atmosphere is generally fairly pleasant and enjoyable.

You are not very hungry and simply want to eat a large starter plate, such as a large Greek salad. The waiter presents you with a menu of freshly prepared starter plates. You check out the starter plates in the written menu and ask for the one that you prefer. The waiter takes your order and will later bring you the chosen plate together with a bread basket.

The restaurant is running a new pricing mechanism in which you are entirely free to decide how much you want to pay for the meal (including zero). You have to make your payment decision BEFORE you have your meal.

Based on this description, what is the amount you would decide to pay?

\section{Scenario 3 (high process-low food uncertainty):}

Imagine that you go out for dinner to a family-owned restaurant of an average price range in your town or city.

You have heard that the service process in the restaurant in terms of friendliness, waiting time and atmosphere can vary a lot. Whereas on average the service process in the 
How certain are you with regard to the level of service quality that you can expect?

$\begin{array}{clllll}\square 1 \quad \square 2 & \square 3 & \square 4 & \square 5 & \square 6 & \square 7 \\ \text { Very uncertain } & & & & & \text { Very certain }\end{array}$

What level of food quality would you expect to receive?

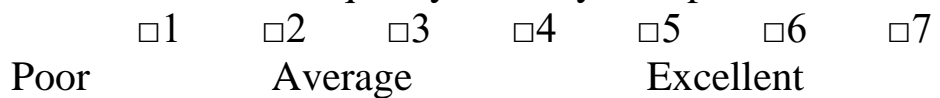

What level of service quality would you expect to receive?

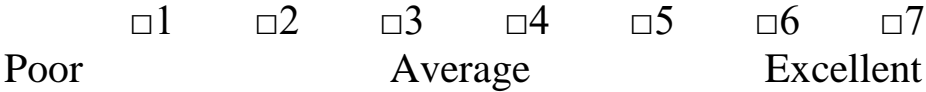

What specific starter dish did you have in mind when you decided on the price?

What would be an approximate regular price of the starter dish you chose?

$£$ 